\title{
ESPAÇOS DE ATUAÇÃO DO PEDAGOGO
}

\author{
Erci Gonçalves de Oliveira \\ Geni de Fátima Bilinski \\ Marta Regina Rodrigues Vieira
}

\begin{abstract}
Resumo
A educação não está centrada apenas dentro do espaço escolar, um ambiente formal de ensino, ela pode ser encontrada em espaços não formais como, igrejas, hospitais, associações, ONGs e outros. Diante dessa afirmação o presente artigo tem como objetivo identificar as diversas áreas de atuação do profissional pedagogo, questionando quais outros ambientes permitem que o professor trabalhe com o processo educacional, levando em consideração que atualmente influenciados pela globalização, por mudanças exigidas pelo mercado de trabalho e pelo próprio sistema de ensino aprendizagem, este profissional tem buscado um espaço de atuação mais amplo, que vai além da sala de aula e dos muros escolares. Para a realização deste, foi adotado uma abordagem bibliográfica, elencando linhas de pensamentos diversas e apresentando um leque de novas possibilidades que atualmente se abrem.
\end{abstract}

Palavras-chave: educação, ensino e educador.

\section{Introdução}

A educação é essencial para o desenvolvimento humano, tanto nos aspectos sociais quanto nos profissionais, como a legislação brasileira apresenta, a educação é um direito de cada indivíduo, "[...] será promovida e incentivada com a colaboração da sociedade, visando ao pleno desenvolvimento da pessoa, seu preparo para o exercício da cidadania e sua qualificação para o trabalho" (BRASIL, 1988).

O processo educacional se divide em educação formal e não formal, sendo o primeiro orientado em um sistema de ensino estruturado e sistemático, pautado em objetivos que desenvolvam a aprendizagem e o conhecimento, já o segundo é planejado na ação, trabalhando com a troca de conhecimentos, processos interativos e construção de saberes coletivos a partir da experiência e do contato social, é importante apontar que ambos os processos podem ser utilizados concomitantemente (LIMA et al., 2019). Desse modo, Arantes (2008) comenta que o ato educativo é um processo que se desenvolve ao longo do tempo, de forma contínua e permanente.

Reconhecendo que o processo de ensino pode ser desenvolvido fora dos muros escolares, se torna claro a necessidade de professores que atuem em outros ambientes. A partir desta 
percepção se desenvolve os questionamentos: Quais espaços o profissional pedagogo está apto a atuar? Durante o curso de graduação este profissional é preparado de forma adequada para trabalhar em outros ambientes que não seja a escola? Considerando as questões, este trabalho apresentara ideias de autores que já pesquisaram sobre essa expansão e a importância da mesma no mercado de trabalho.

\section{Contexto Histórico: o Curso de Pedagogia}

No decorrer da história, a formação no curso de pedagogia passou por várias alterações curriculares, diversas abordagens epistemológicas e socioculturais foram modificadas, bem como a influência do cenário político e econômico em todo meio educacional, esses e outros fatores foram essenciais para formar o curso que se conhece atualmente (CRESPI e NÓBILE, 2018).

O curso de pedagogia no Brasil tem datado como marco inicial a década de 30, autores comentam que o mesmo surgiu "como consequência da preocupação com a formação de docentes para o curso normal" (ARANTES e GEBRAN, 2014, p. 2). A primeira institucionalização do curso foi por meio do Decreto-Lei 1190/1939, sendo criado na modalidade de bacharelado, com duração de três anos, objetivando a formação profissionais técnicos em educação, sequencialmente criou-se também o curso de Didática na modalidade licenciatura, o mesmo funcionava da seguinte forma, quando concluído os três anos de bacharel o aluno teria a opção de completar mais um ano e adquirir o título de licenciado (ARANTES e GEBRAN, 2014).

O Decreto-Lei 1190/1939 se manteve em vigor até 1961, neste ano foi aprovado a primeira Lei de Diretrizes e Bases da Educação (Lei 4024/1961). Em 1962 foi criado o Parecer do Conselho Federal de Educação (CFE) no 251/1962, em atendimento a LDB. Em 1969 com o Parecer do CFE no 252/1969 e a Resolução do CFE n 2/1969, foram fixados novos parâmetros no âmbito de conformidade e funcionamento do curso, foi a partir destes que a didática se tornou obrigatório, logo a opção do curso em licenciatura se tornou evidente sobre o bacharel (CRESPI e NÓBILE, 2018).

Nos anos que se seguiram as discussões sobre a formação profissional do pedagogo foram intensificadas e em 1996 foi criado a nova Lei de Diretrizes e Bases (Lei 9394/1996) que está em vigor até os dias atuais. Com base nesta Lei tem surgido várias instruções 
normativas, resoluções, pareceres e Leis que continuam sendo publicadas, visando a melhoria na qualidade do sistema de ensino brasileiro, tanto na rede pública, como na rede privada (BAPTAGLIN e ROSSETO, 2012).

Sobre o questionamento de formação adequada para profissionais pedagogos que atuam em diversos ambientes a Resolução CNE n 1/2006 extinguiu as habilitações, definindo a docência como base de formação do pedagogo, apresentando um leque de possibilidades para a atuação do licenciado, considerando que o curso se aplica

\footnotetext{
à formação inicial para o exercício da docência na Educação Infantil e nos anos iniciais do Ensino Fundamental, nos cursos de Ensino Médio de modalidade Normal e em cursos de Educação Profissional, na área de serviços e apoio escolar, bem como em outras áreas nas quais sejam previstos conhecimentos pedagógicos (BRASIL, 2006, p. 6).
}

Diniz e Dias (2009) comentam que as universidades têm a responsabilidade de ofertarem cursos de graduação que antecipem as exigências da sociedade, pois a partir das alterações legais e das cobranças sociais o curso de pedagogia perpassa por modificações curriculares a fim de preparar o profissional a superar os muros escolares. Porém para Cabrera (2013) ainda existe um logo caminho a ser percorrido, uma vez que em muitas instituições o curso ainda mantém seu foco muito centrado na atuação no espaço escolar.

\section{Espaços escolares e não escolares}

Pensar em educação fora de sala de aula é um desafio, pois esse processo se desenvolve em espaços familiares, no bairro, em espaços de lazer, em igrejas, ou mesmo entre grupos de amigos da escola, é um processo pedagógico, sociopolítico e cultural, muitas vezes deixado de lado por não seguir modelos estruturados de trabalho. Porém nos últimos anos a discussão sobre atuação do pedagogo em espaços não escolares tem ganhado notoriedade, fato este, que se relaciona diretamente ao processo de educação não formal (GOHN, 2014).

Diante do exposto autores pontuam que para o pedagogo ser inserido em espaços não escolares, a educação precisa ser trabalhada como um fenômeno que abrange também os aspectos sociais, políticos e econômicos, pois atuando como articulador de aprendizagem ante de um sistema globalizado, este profissional influencia a vida em sociedade, movimentos culturais e intelectuais, tornando-se o mediador da problemática educativa em todos os espaços. É preciso reconhecer também, que independentemente do local de trabalho, o pedagogo tem como concepção básica a formação humana, a formação de cidadãos 
emancipados e pragmáticos, que reconhecem suas responsabilidades, e colaboram com a comunidade que os cercam (ARAUJO et al, 2016; DINIZ e DIAS, 2009; GOHN, 2014; LIBANO, 1999).

Dentro do espaço escolar o trabalho do pedagogo vai além da regência em sala de aula, o mesmo pode atuar na coordenação, supervisão e orientação pedagógica e administração escolar. Fora dos muros escolares este profissional pode atuar em zoológicos, brinquedotecas, hospitais, dentro de empresas com recursos humanos, com políticas públicas, organizações como conselhos tutelares e organizações não governamentais, entre outros (ALMEIDA, 2006).

Frison (2006) traz em seus estudos que em organizações o pedagogo trabalha com a formação e capacitação de trabalhadores, com práticas educativas, com acompanhamento de desempenho pessoal, desse modo criando condições para um bom desempenho profissional. Para Aquino (2011) em hospitais o pedagogo vai trabalhar com crianças e adolescentes os aspectos emocionais, afetivos e cognitivos. Ainda em hospitais o profissional pode desenvolver o acompanhamento de pessoas com algum comprometimento mental, em parceria com uma equipe multidisciplinar, utilizando o lúdico/cognitivo por meio de teatros e recreações.

Freitas (2012) suas pesquisas sobre o trabalho do pedagogo no tribunal de justiça do estado do Pará, identificou que este pode atuar na elaboração de estudos de caso, laudos, pareceres e avaliações de acordo com as necessidades do juízo, fazer visitas domiciliares com vistas a obtenção de informações da situação psicossocial de menores e também realizando entrevistas com menores e seus tutores, porém estas funções podem ser variáveis de acordo com a vara onde o profissional é lotado.

De acordo com Fireman (2006) em sindicatos o pedagogo atua com planejamento, coordenação e execução de projetos, visando a qualificação e requalificação para manutenção da empregabilidade. Na área do turismo, desenvolve atividades educativas a fim de proporcionar o conhecimento da localidade, história e cultura. Ainda de acordo com a autora o trabalho do profissional pedagogo em museus, clubes, parques e ambientes recreativos está sempre relacionado a formação humana, posição que condiz com os autores Araujo et al (2016), Diniz e Dias (2009) e Libano (1999) já citados anteriormente.

"Devido à valorização social do conhecimento, os pedagogos tornaram-se bem requisitado em espaços, porém muito ainda se questiona sobre a atuação desses profissionais 
em instituições não escolares" (ARAÚJO et al, 2016, p. 4). Com está afirmação e considerando a linha de pensamento dos autores citados, vale comentar que a pedagogia tem se desenvolvido em lugares que a pouco tempo atrás não se imaginava possível, mas as discussões a esse respeito ainda precisam de mais espaço e notoriedade, especialmente em salas de aulas dos cursos de pedagogia.

\section{Conclusão}

A realização deste trabalho permitiu uma reflexão sobre a importância dos professores para a sociedade atual, bem como a importância da formação acadêmica que abrange questões teóricas, técnicas e práticas. É imprescindível que durante seu processo formação o educador tenha a oportunidade conhecer as diversas atuações que o mesmo poderá desenvolver na sociedade, uma vez que a cada dia a visão de mundo tem se ampliado e sua presença tem se tornado necessária nos mais diferentes locais de trabalho.

Se confirma então, que o pedagogo pode sim atuar em espaços que vão além dos muros escolares, desenvolvendo a educação formal e não formal de maneira ambas se complementem, assim o aprendizado circula todos os âmbitos da sociedade, diversificando saberes, levando e trazendo novas ideias e novos subsídios, visando um único objetivo que é oferecer uma educação de qualidade para todos, independente de idade e local, afinal esse é um processo contínuo e permanente.

\section{Referências}

ALMEIDA, M.G. Pedagogia empresarial: saberes, práticas e referências. Rio de Janeiro: Brasport, 2006.

ARANTES, V. A. et al. Educação formal e não formal. São Paulo: Summus, 2008.

ARANTES, A. P. P.; GEBRAN, R. A. O curso de pedagogia e o processo de formação do pedagogo no brasil: percurso histórico e marcos legais. Holos, v. 6, ano 30, 2014.

ARAÚJO, J. A. et al. Atuação do pedagogo no espaço não escolar: o caso do centro de integração empresa escola - CIEE. In: III CONGRESSO NACIONAL DE EDUCAÇÃO, 2016, Natal: Editora Realize, 2016.

AQUINO, S. L. O pedagogo e seus espaços de atuação nas representações sociais de egressos do curso de pedagogia. Dissertação (Mestrado em Educação) - Universidade Federal de Viçosa, Viçosa, 2011.

BAPTAGLIN, L. A.; ROSSETO, G. A. S. Formação Inicial no curso de Pedagogia: a atividade docente de estudo e a aprendizagem da docência. In: IX ANPED SUL, 2012, Caxias do Sul: UCS, 2012. v. 9. p. 1-15. 
BRASIL. Constituição (1988). Constituição da República Federativa do Brasil. Brasília: Senado Federal, 1988.

BRASIL. Lei de Diretrizes e Bases da Educação Nacional, LDB. 9394/1996.

BRASIL. Conselho Nacional de Educação. Resolução n 1/2006 de 15 de maio de 2006. Institui Diretrizes Curriculares Nacionais para o Curso de Graduação em Pedagogia, licenciatura. Diário Oficial da União, Brasília, 2006.

CRESPI, L.; NÓBILE, M. F. Trajetória histórica do curso de graduação em Pedagogia: principais documentos legais e contexto atual da oferta no Brasil. Revista Eletrônica de Educação. v. 12, p. 319-335, 2018.

DINIZ, P. S.; DIAS, T. B. M. Pedagogo em espaços não-escolares. Trabalho de Conclusão de Curso (Graduação em Pedagogia) - Faculdade São Luís de França: 2009.

FIREMAN, M. D. O trabalho do pedagogo na instituição não escolar. Dissertação (Mestrado em Educação) - Universidade Federal do Pará, Belém, 2006.

FREITAS, R. C. F. O trabalho do pedagogo no tribunal de justiça do Pará: os desafios da inovação no exercício profissional. Dissertação (Mestrado em Educação) - Universidade Federal de Alagoas, Alagoas, 2012.

FRISON, L. M. B. Auto-regulação da aprendizagem: atuação do pedagogo em espaços não-escolares. 2006. 342f. Tese (Doutorado em Educação) - Pontifícia Universidade Católica do Rio Grande do Sul, Porto Alegre, 2006.

GOHN, M. G. M. Educação não formal, aprendizagens e saberes em processos participativos. Investigar em Educação, v. 1, p. 35-50, 2014.

LIBÂNEO, José Carlos. Pedagogia e Pedagogos, para quê? São Paulo: Cortez, 1999.

LIMA, E. I. et al. O papel da educação formal, não formal e informal na formação política de mulheres educadoras. Revista Pegada. v. 20. n. 1. 2019. 